\title{
Research Paper: Evaluating Psychometric Characteristics of Detection Protocol of Malingering Stuttering
}

\author{
Arsia Thaghva ${ }^{1},{ }^{*}$ Majid Saleh ${ }^{1}$, Vahid Donyavi ${ }^{1}$, Bijan Shafei $^{2}$, Meisam Shafei $^{2}$, Ahmad Pourmohamad ${ }^{3}$
}

1. Department of Psychiatry, School of Medicine, AJA University of Medical Sciences, Tehran, Iran.

2. Department of Speech Therapy, Faculty of Rehabilitation Sciences, Isfahan University of Medical Sciences, Isfahan, Iran.

3. Department of Speech Therapy, Faculty of Paramedical Sciences, Mashhad University of Medical Sciences, Mashhad, Iran.

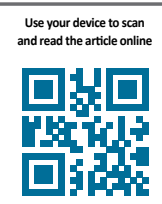

Clftation: Thaghva A, Saleh M, Donyavi V, Shafei B, Shafei M, Pourmohamad A. [Evaluating Psychometric Characteristics of Detection Protocol of Malingering Stuttering (Persian)]. Archives of Rehabilitation. 2017; 18(2):154-163. http://dx.doi. org $/ 10.21859 /$ jrehab-1802150

: http://dx.doi.org/10.21859/jrehab-1802150

Received: 03 Dec. 2016 Accepted: 19 Mar. 2017

Keywords: stuttering, Malingering, Psychometric, Protocol

\section{ABSTRACT}

Objective Stuttering is a disorder in fluency that is identified through involuntary interruptions in continuous speech. There are different types of the disorder, including growth stuttering with acquired and malingering origins. With respect to the law of exemption of stuttering individuals from military service, the issue of malingering is quite common. Since there is no standard tool to be used for deciding exemption, experts rely mostly on their personal knowledge and judgment, and because the measurements and perceptual judgments are made informally, it increases the likelihood of errors. Therefore, the preparation of a protocol to detect conscripts who are afflicted with malingered stuttering from those who suffer from real stuttering was the aim of the study, thereby, determining the conditions of exemption from military service.

Materials \& Methods This study is of validation type. Accessible simple non-probability sampling was used. First, different sections of the detection protocol of malingering stuttering was prepared, which consisted of structured interview, questionnaire for malingering stuttering, MMPI test, facilitator techniques, SSI4 test, and analysis of reading and speech sample. Then, sampling was done on 20 exemption applicants who were suspected to be malingering and, at the same time, on 15 applicants who had visited a clinic for a real stutter. Then, the features of the protocol were investigated, and the profile of malingering was prepared based on the results obtained from the detection protocol of malingered stuttering. Finally, the data were analyzed using different statistical methods and SPSS.

Results Detection protocol of malingered stuttering was codified. With regard to Cronbach's alpha coefficient, which was equal to 0.76 , for the detection questionnaire of malingered stuttering, the questionnaire was of good internal consistency. To determine the concurrent validity of the protocol (the results of the implementation of the protocol following the opinion of psychiatrists), Chi-square test was carried out, and no significant difference was found between the protocol and the comments of the psychiatrists $(P>0.05)$. The protocol was of good construct validity. Finally, a profile was prepared to determine the status of conscription with respect to stuttering disorder based on the results for each participant. Conclusion According to the results, the detection protocol of malingering stuttering is of good internal consistency and concurrent validity. However, considering that the sample population was not large in the present study, it can be said that this study is a preliminary evaluation to find the psychometric features of the instruments, with the aim of laying the groundwork for further studies.

\footnotetext{
* Corresponding Author:

Majid Saleh, MSc.

Address: Department of Psychiatry, School of Medicine, AJA University of Medical Sciences, Tehran, Iran.

Tel: +98 (913) 9796971

E-Mail: Majid_saleh_slp@yahoo.com
} 


\title{
بررسى ويزّكىهاى روان سنجى برنامه تشخيص لكنت تمارضى
}

\author{
ارسيا تقوا'، "مجيد صالح'، وحيد دنيوى'، بيزن شفيعى'، ميثم شفيعى '؟ احمد يورمحمد؟ \\ ا 1- كروه روانيزشكى، دانشكده يزشكى، دانشعاه علوم يزُشكى ارتش، تهران، ايران.

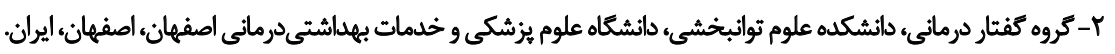

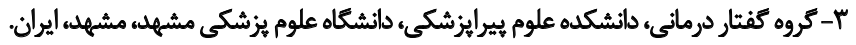

\begin{abstract}
حكبد

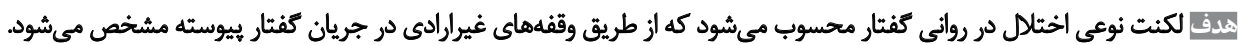

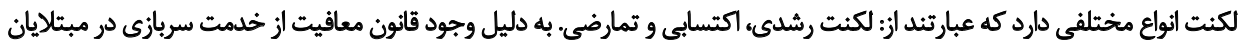

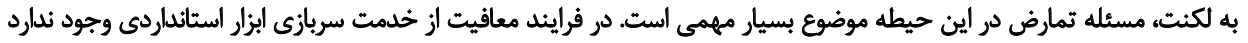

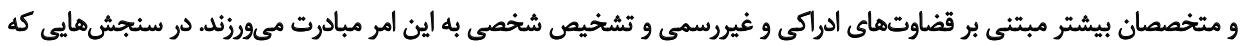

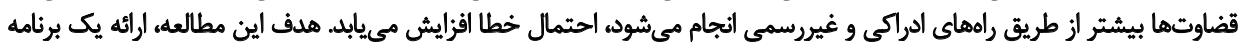

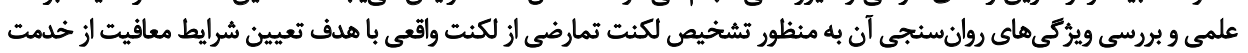
سربازى است.

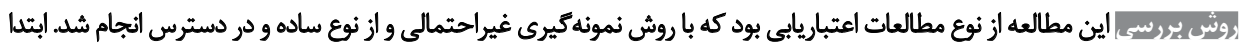

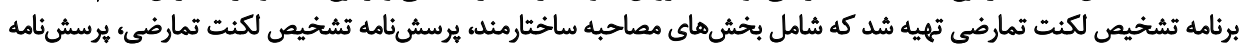

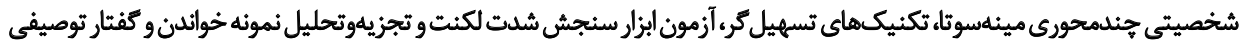

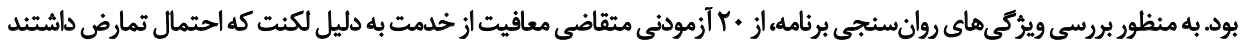

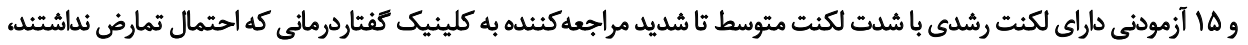

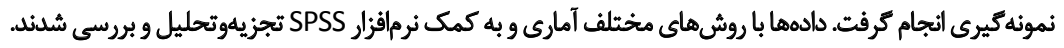

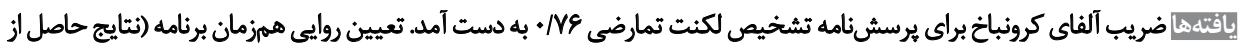

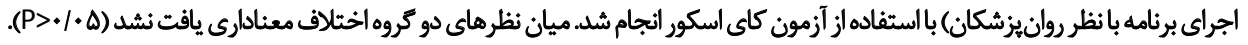

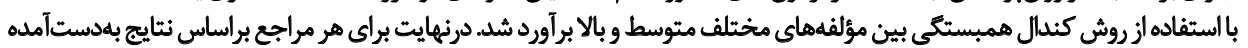

$$
\text { نيمزغ ترسيهم شد. }
$$

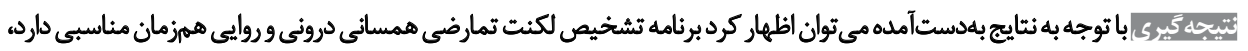

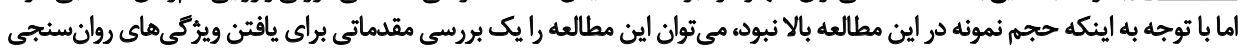

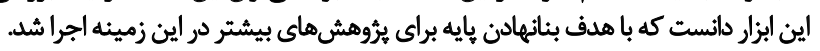

تاريخ دريافت: "آ آذر هوش

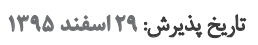

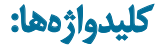

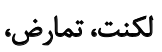 \\ روانسنجى، برنامه
}

تا ا درصد تخمين زده مىشود [عابّ]. لكنت انواع مختلفى دارد؛

مقدمه

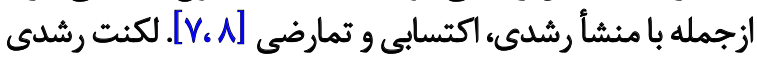

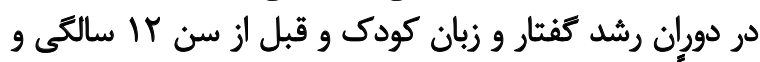

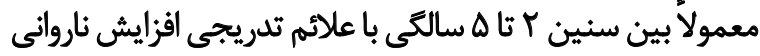

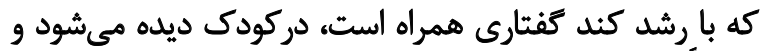

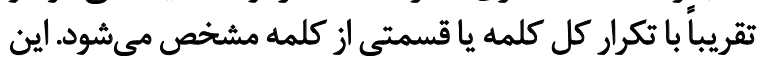

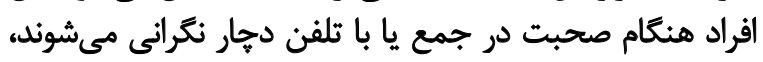

الكنت بديداى فوقالعاده بييجيده در كستره علوم شناختي

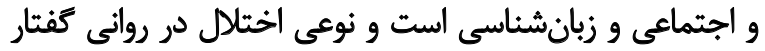

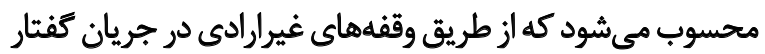

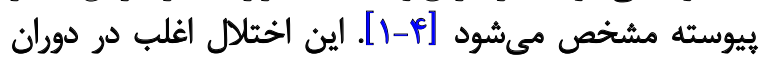

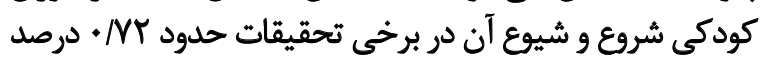


اندكى به اين موضوع تخصيص يافتهاند و كمتر به آن توجه شده آنداه

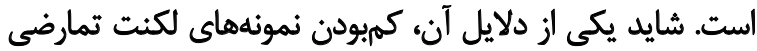

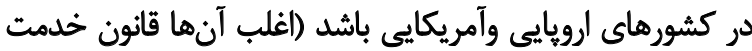

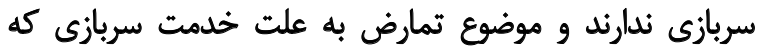

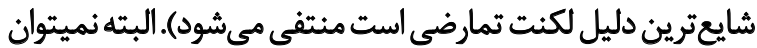

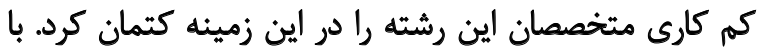

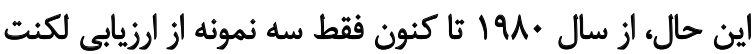

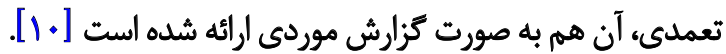
در سال 1919 إِركى مأمور ارزيابى و تشخيص لكنت يك مرد

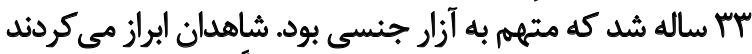

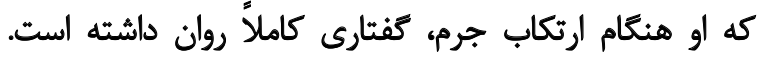

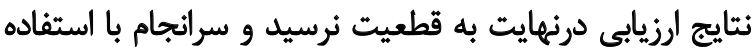

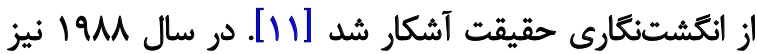

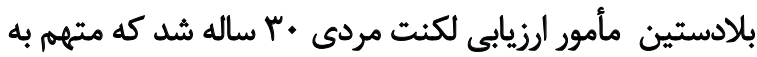

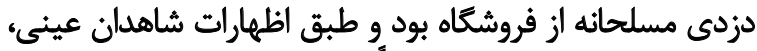

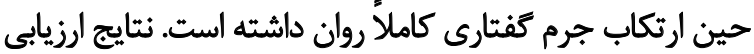

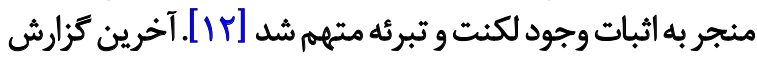

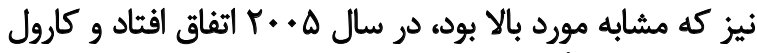

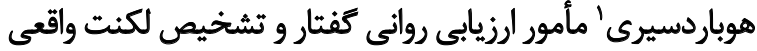

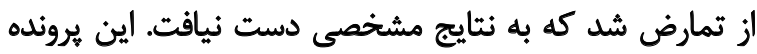

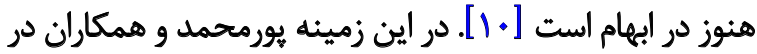

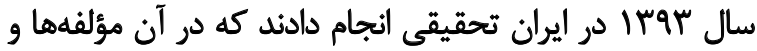

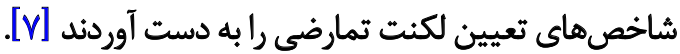
به نظر مىرسد در كشور ما به دليل آمار بالاى تصادفات و ماند

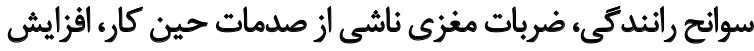

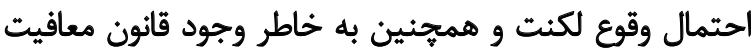

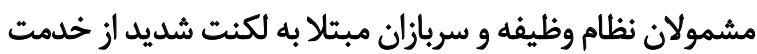

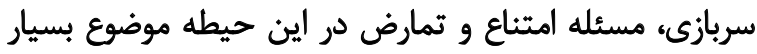

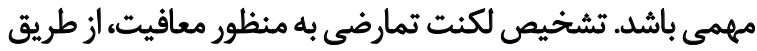

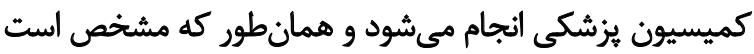

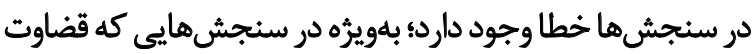

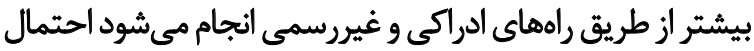

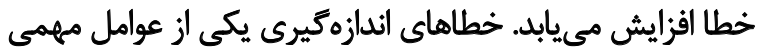

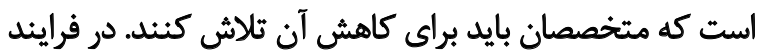

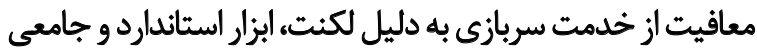

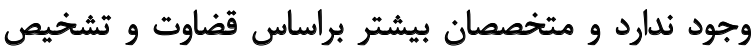

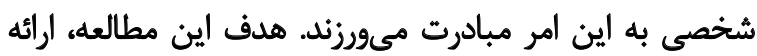

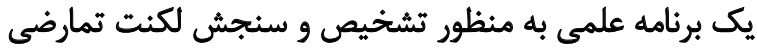

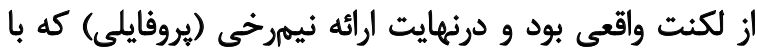

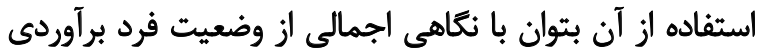

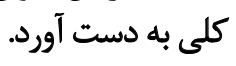

1. Carol hoobardseery

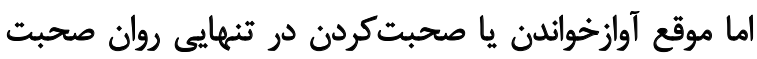

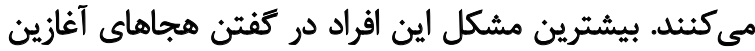

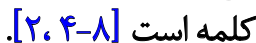

لكنت اكتسابى نادرتر از لكنت رشدى است. اين نوع لكنت در

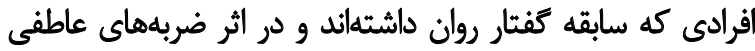

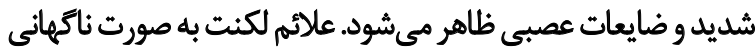

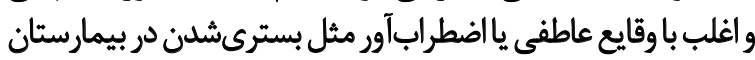

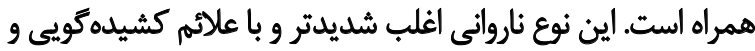

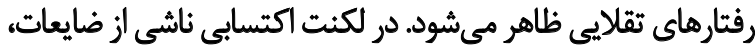

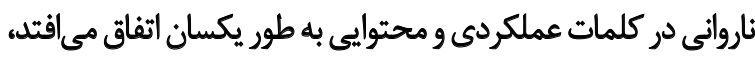

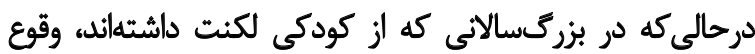

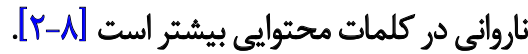

سومين نوع لكنت، لكنت تمارضى است. در اين نوع لكنت، فرد

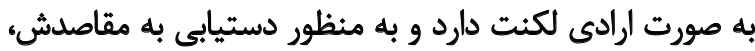

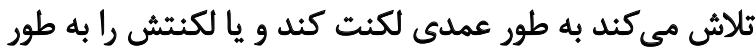

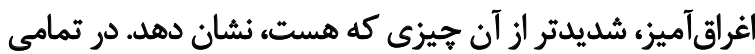

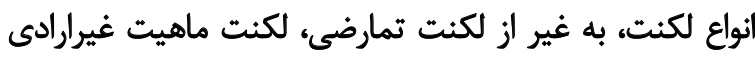

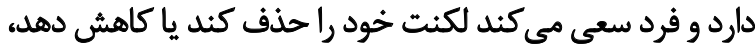

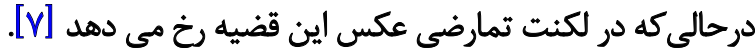

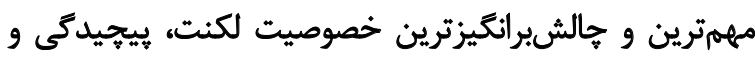

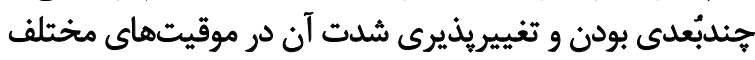

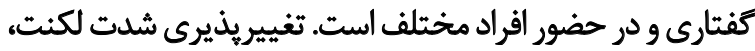

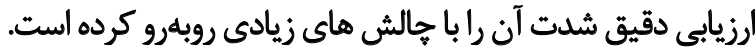

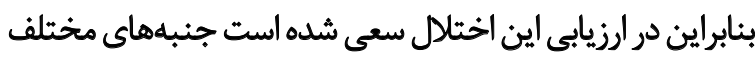

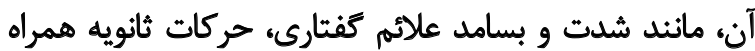

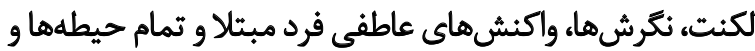

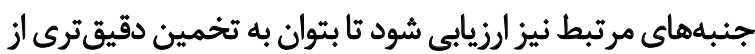

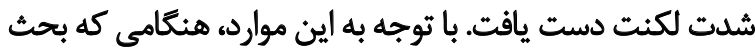
تمارض در اين حيطه مطرح باشده

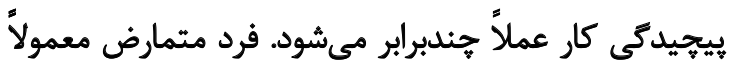

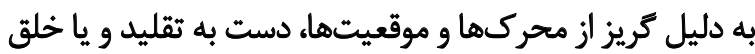

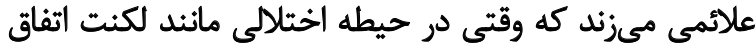

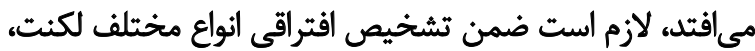

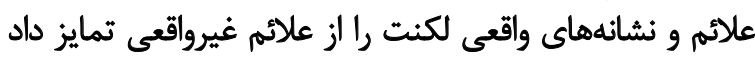

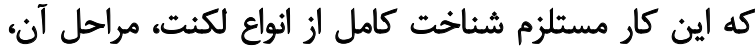

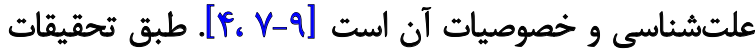

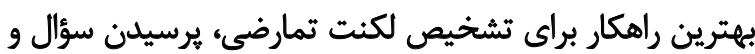

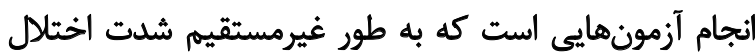

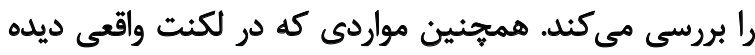

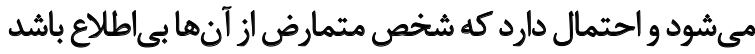

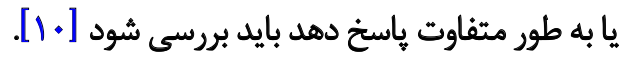
مثأسفانه در منابع تحقيقاتى و كثابخانههاى الكترونيك مقالات 
مينهسوتا استفاده شده است. اين آزمون مقياسهاى بالينى

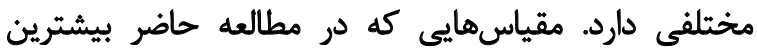

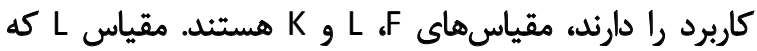

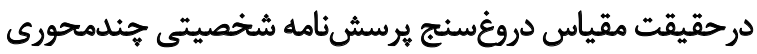

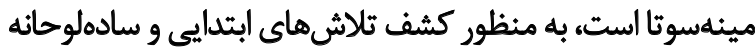

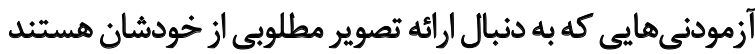

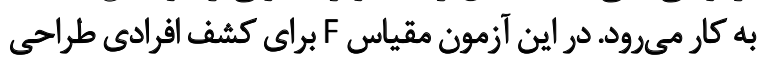

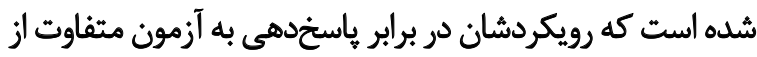

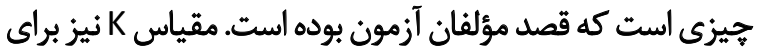

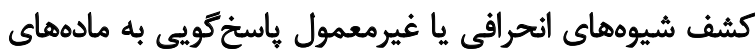

آزمون طراحى شدهاست [IV]

بخش جهارم برنامه شامل تكنيكهاى تسهيل ترك بود. در اين

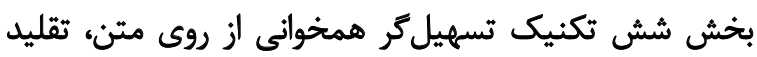

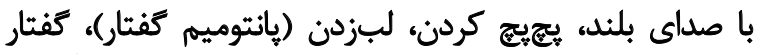

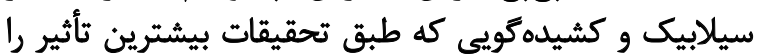

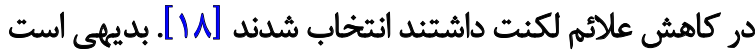

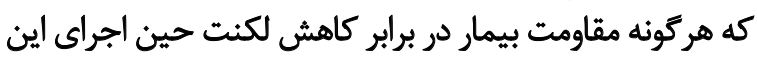

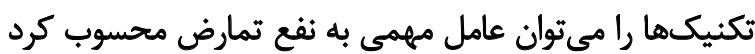

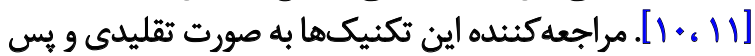

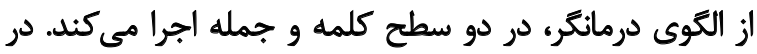

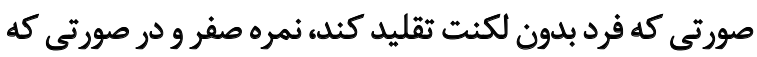

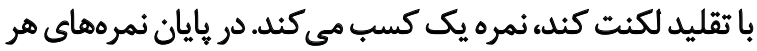

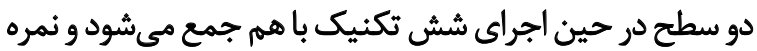

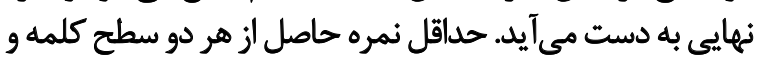
جمله در شش تكنيك، صفر و حداكثر نمره ب ال است.

به دليل اينكه شدت لكنت در تعيين نوع معافيت از خدمت

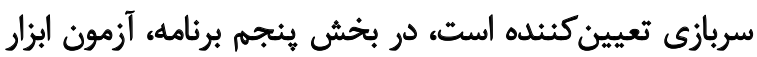

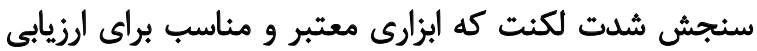

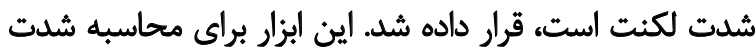

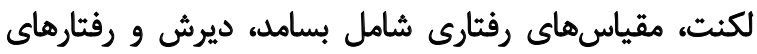

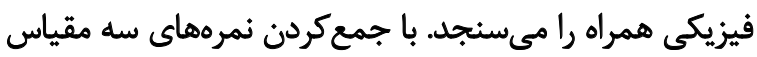

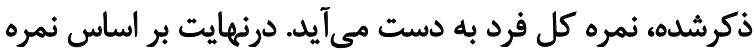

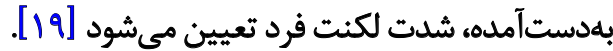
بخش ششم اين برنامه در رابطه با تجزيهوتحليل نمونه تونه كفتار

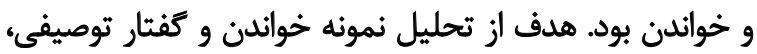

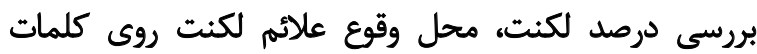

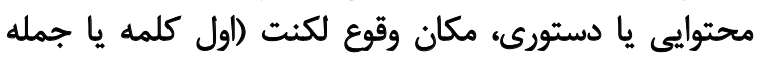

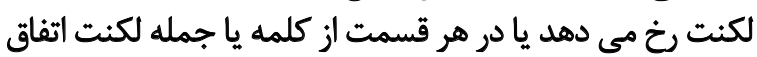

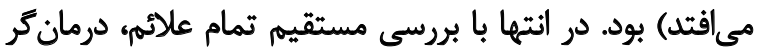

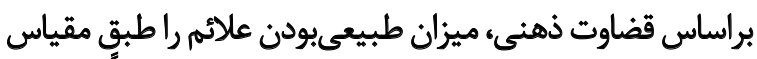

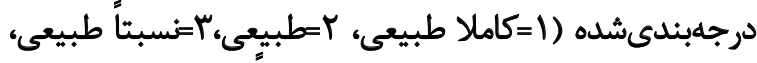
F

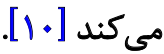

ووش بروسى

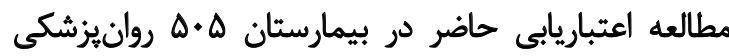

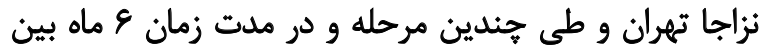

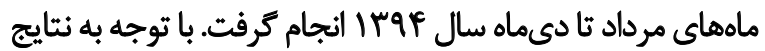

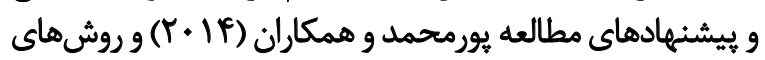

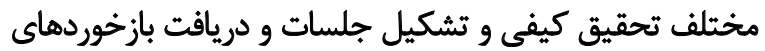

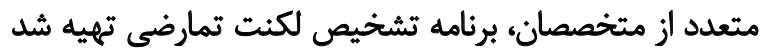

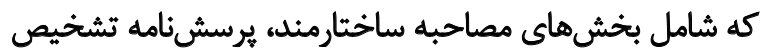

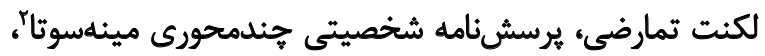

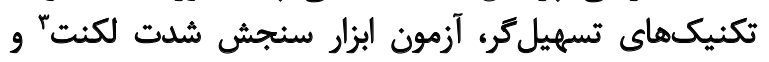

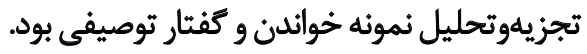

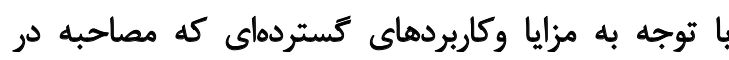

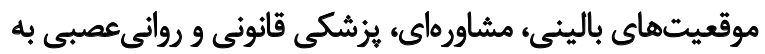

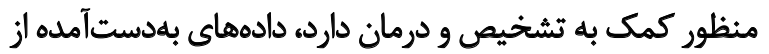

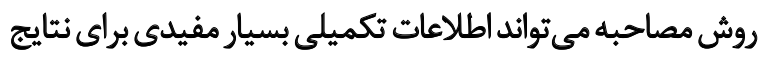

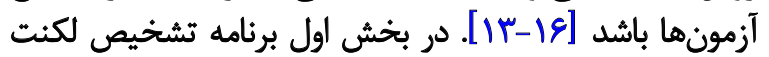

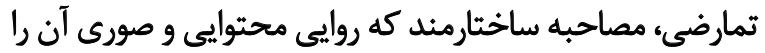

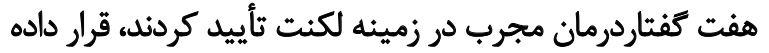

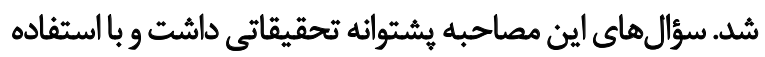

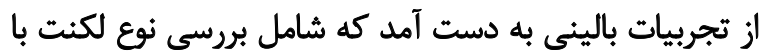

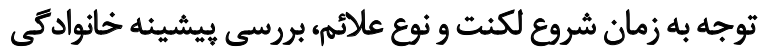

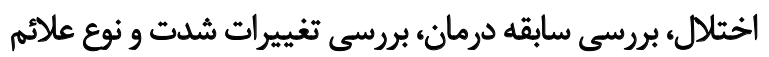

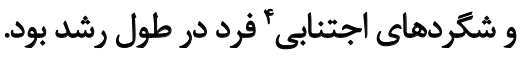

در بخش دوم برنامه تشخيص لكنت تمارضى از يرسشنامهام

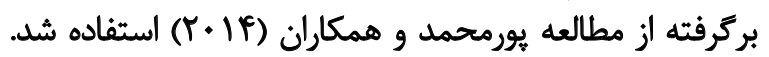

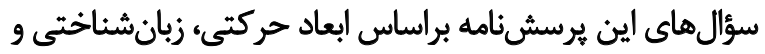

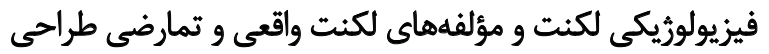

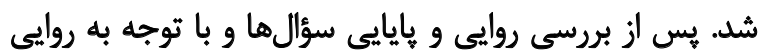

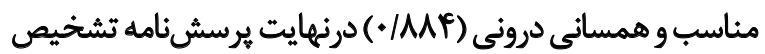

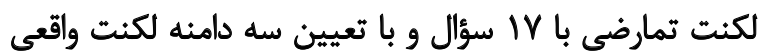

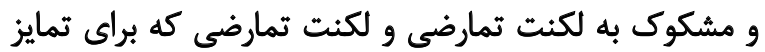

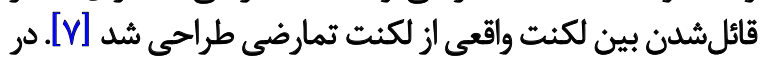

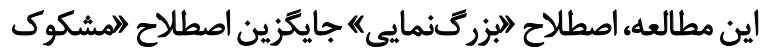

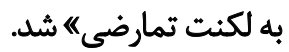

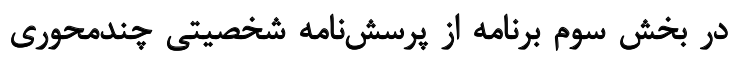

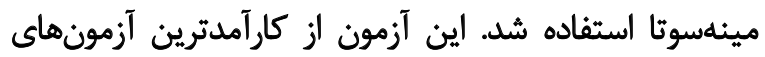

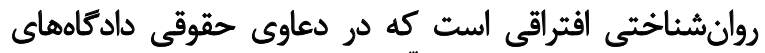

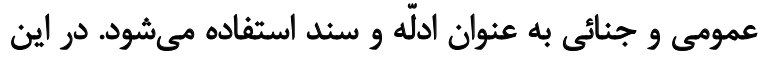

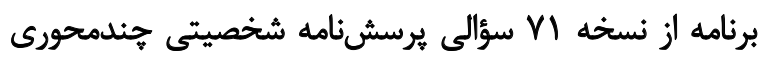

4. Avoidance techniques 


\begin{tabular}{|c|c|}
\hline معاف دائم & شيد \\
\hline معاف از sزم & خفيف تامتوسط \\
\hline 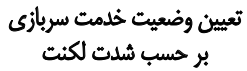 & شيت لكنت بر حسب \\
\hline
\end{tabular}

توانبخننى

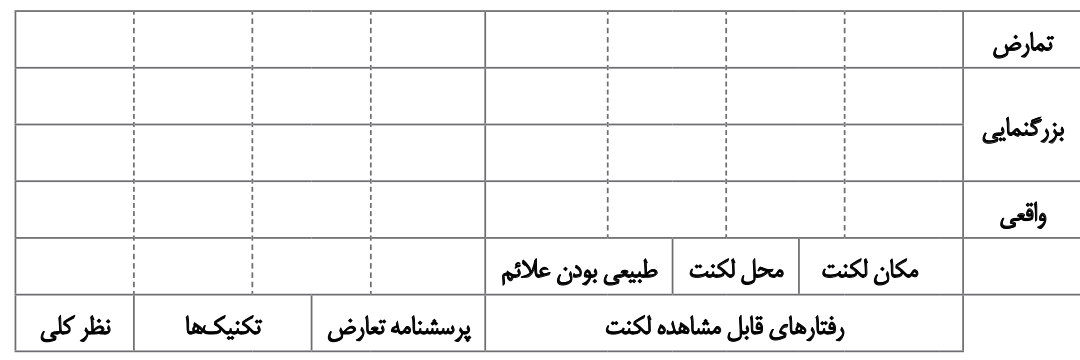

تصوير ا. نيهرخ تعيين وضعيت خدمت سربازى به واسطه اختلال لكنت
كاى اسكور و همسانى درونى با استفاده از روش آلفاى كرونباخ

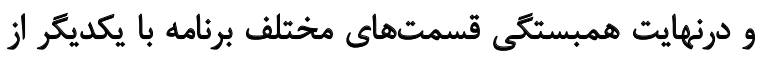

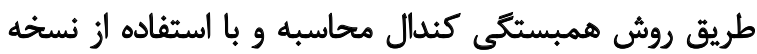

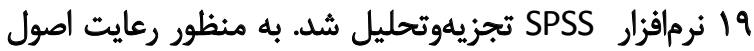

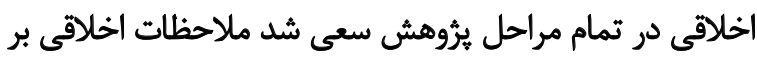

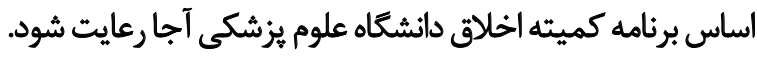

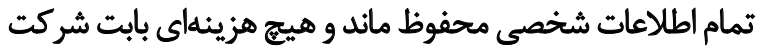

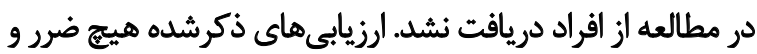
زيانى براي افراد شركت كنئده دربرنداشت دريت.

يافتهها

بنه منظور بررسى برخى از مؤلفههاى برنامه از ها فر فرد داراى

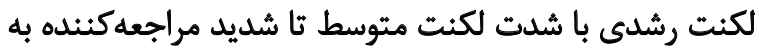

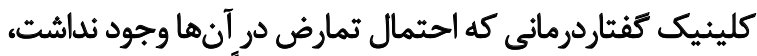

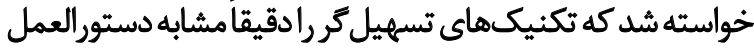

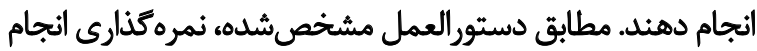

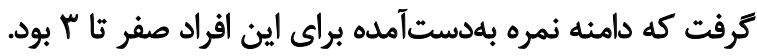

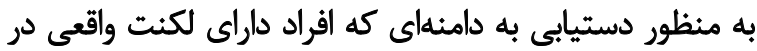

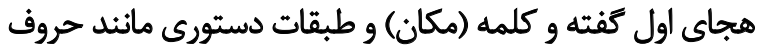

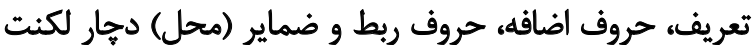

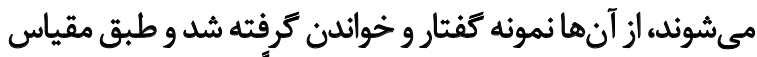

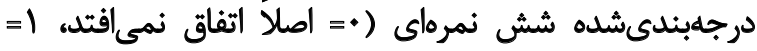

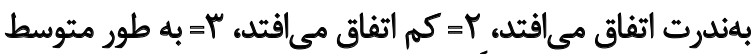

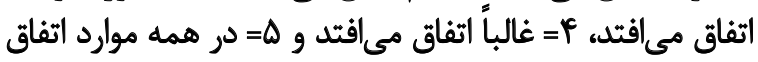

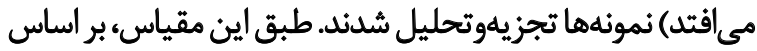

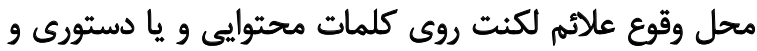

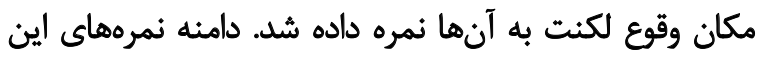

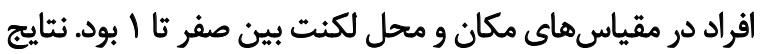
بهدستآمده از اين ها نفر در جدول شماره إن آورده شده است.

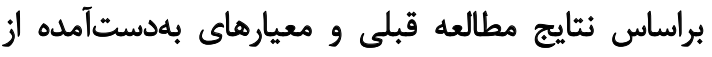

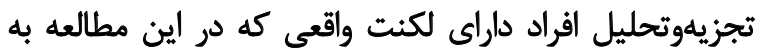

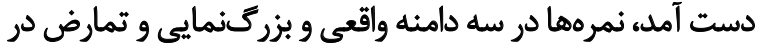

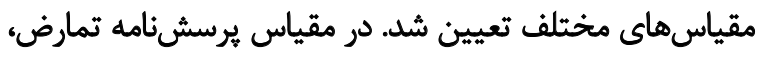

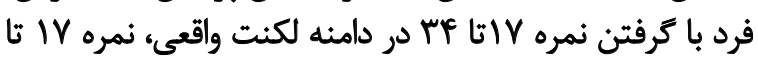
IV

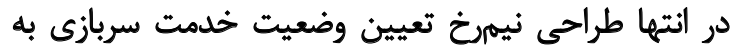

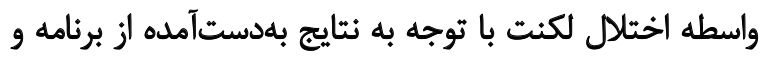

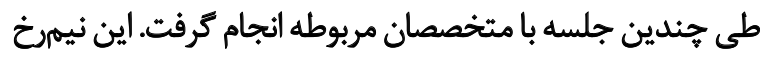

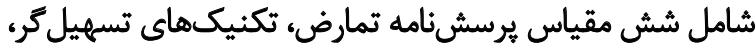

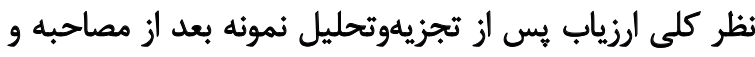

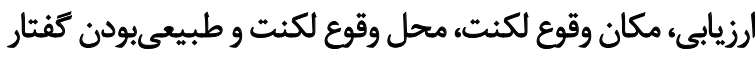

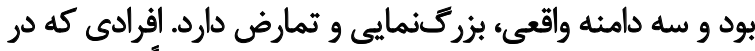

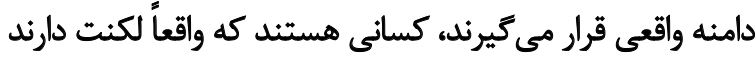

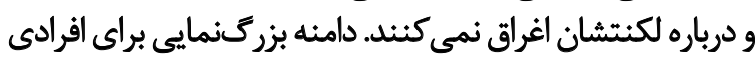

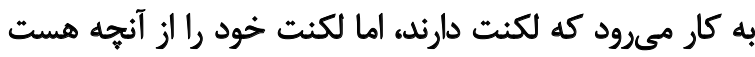

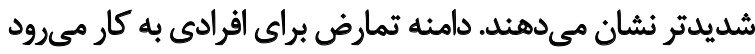

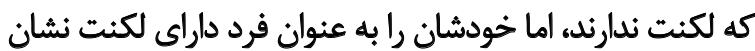

$$
\text { مى مهند (تصوير شماره ()). }
$$

يس از طراحى برنامه تشخيص لكنت تمارضى، در مرحله اول

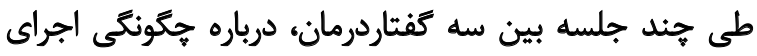

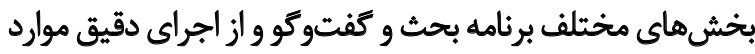

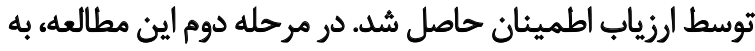

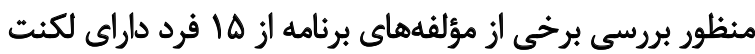

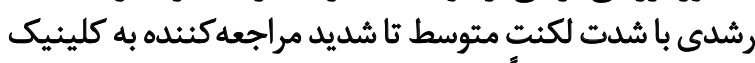

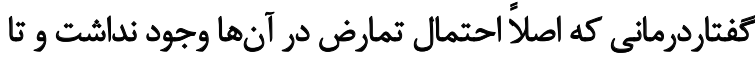

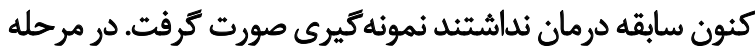

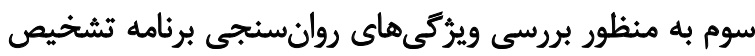

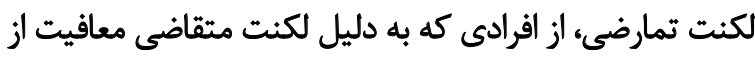

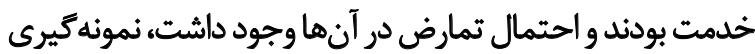

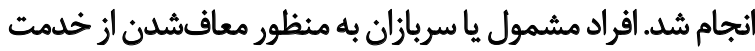

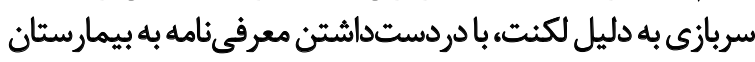

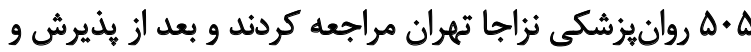

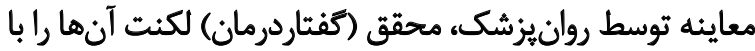

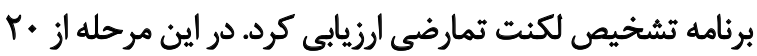

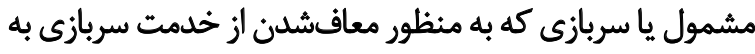
دليل لكنت مراجعه كرده بودند نمونه كيرى شدئ

در مرحله جهارم براى تعيين روايى همزمان برنامه، نتايج

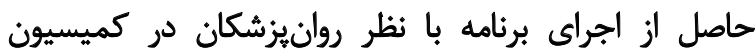

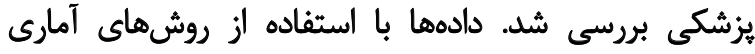
توصيفى تجزيهوتحليل شد. روايى همزمان باد باس استفاده از آزمون آراري 


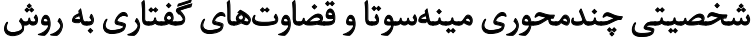

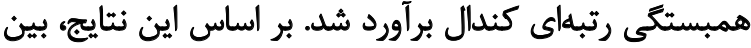

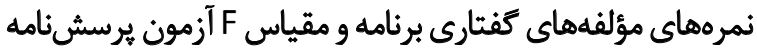

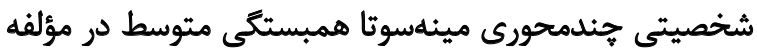

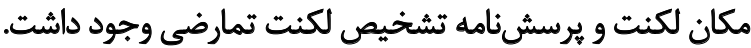

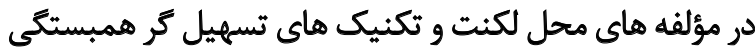

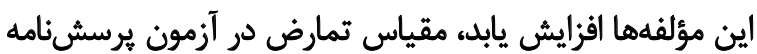

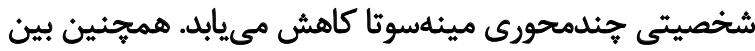

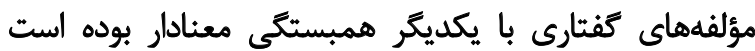

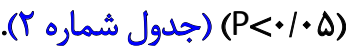

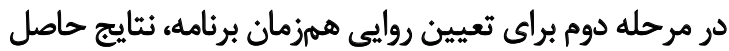

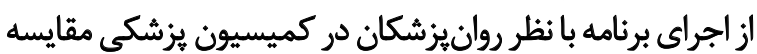

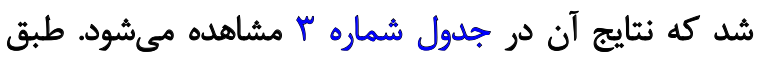

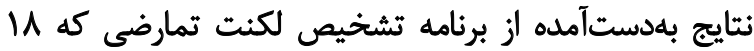

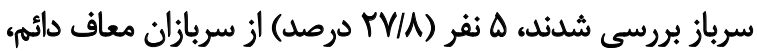

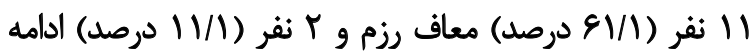

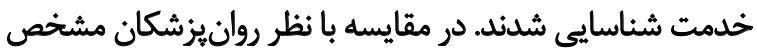

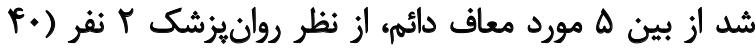

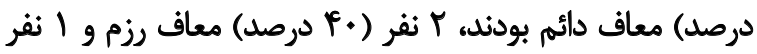

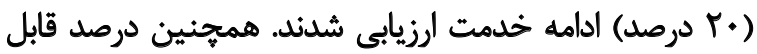

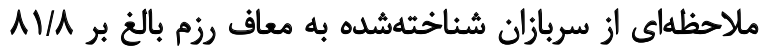

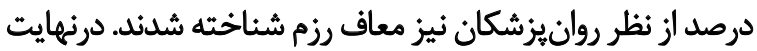

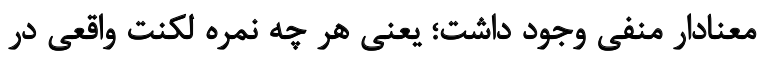

تمارضى قرار مى كيرد. در مقياس تكنيكهاى تسهيل ترك، فرد با

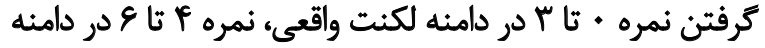

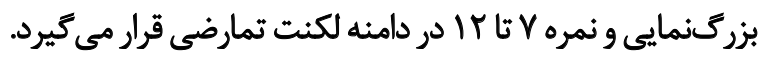

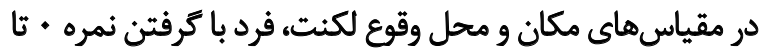

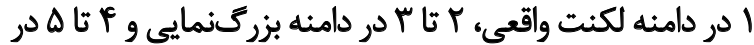

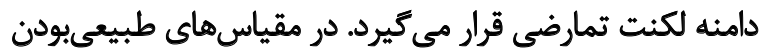
كفتار و نظر كلى ارزياب، فرد با كرفئن

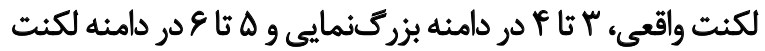

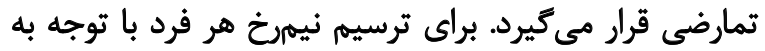

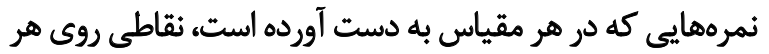

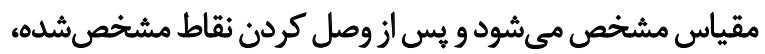

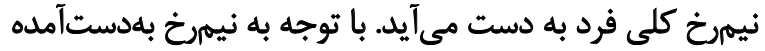

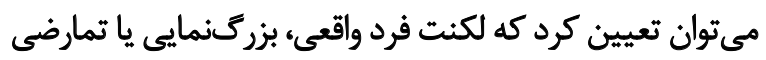

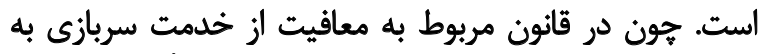

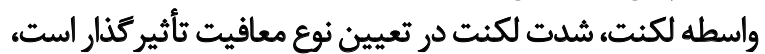
قسمت جداكانهاى كه بر اساس نتايج آزمون ابزار سنجش

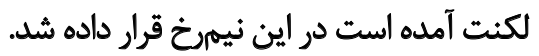
از افرادى كه مثقاضى معافيث از خدمت به دليل لكنت بودند

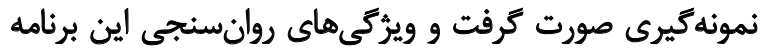

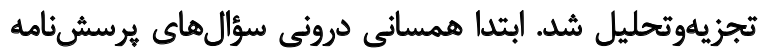

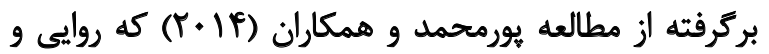

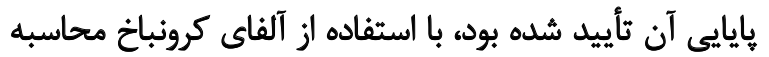

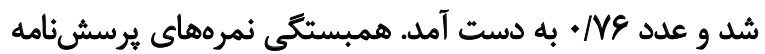

جدول ا. اطلاعات و دامثه نمرههاى ها فرد داراى لكنت واقعى

\begin{tabular}{|c|c|c|c|c|c|}
\hline ثمره در مقياست مكان & نمره در مقياست محل & 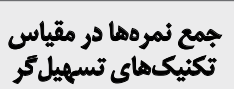 & نوع لكنت & شدت لكنت براساس SSI4 & شماره مراجعلكنده \\
\hline 1 & . & . & رشدى & متوسط & 1 \\
\hline 1 & 1 & - & رشدى & مديد & r \\
\hline . & . & 1 & رشدى & متوسط & r \\
\hline . & 1 & . & رشدى & متوسط & r \\
\hline 1 & 1 & r & رشىى & ش مديد & $\Delta$ \\
\hline 1 & . & • & رشدى & متوسط & 8 \\
\hline 1 & 1 & r & رشدى & | شديد & $v$ \\
\hline . & • & $r$ & رشدى & ش ت شيد & $\wedge$ \\
\hline 1 & 1 & 1 & رشدى & | شديد & 9 \\
\hline . & 1 & . & رشدى & متوسط & 1. \\
\hline 1 & 1 & 1 & رشىى & | شديد & $" 1$ \\
\hline 1 & . & 1 & رشدى & ش شديد & $\pi$ \\
\hline . & . & r & رشلى & | شيد & ir \\
\hline \multirow[t]{2}{*}{1} & . & . & رشدى & متوسط & ip \\
\hline & r & r & ر رشدى & | مديد & 10 \\
\hline
\end{tabular}

توانبفننى 
جدول ז. مقادير همبستكى كندال مؤلفههاي كفتارى برنامه و نمرههاى آزمون يرسش نامه شخصيتى جندمحورى ميئهوتا

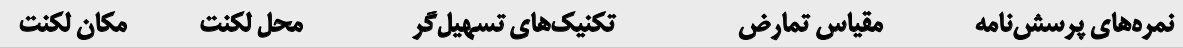

\begin{tabular}{|c|c|c|c|c|c|}
\hline & & & & 1 & 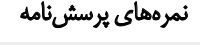 \\
\hline & & & 1 & $\%$ iv & مقياس تمارض \\
\hline & & 1 &.$- / 1 \Delta Y^{*}$ &.$/ m 9$. & تكنيك هاي تسهيل \\
\hline & 1 & $.19 Y \Lambda^{-\infty * *}$ &.$- / 1 \mathrm{re*}$ & $\cdot / \pi q r^{*}$ & محل لكنت \\
\hline 1 & $\cdot M A^{* * * *}$ & . & $+1 \cdot \varphi_{*}$ & $\cdot M T$ & مكان لكنت \\
\hline
\end{tabular}

به طور تقريبى يكسان بوده است (ه> (P>) (جدول شماره f). درنهايت نيمرخ تعيين وضعيت خلدمت سربازى به واسطه

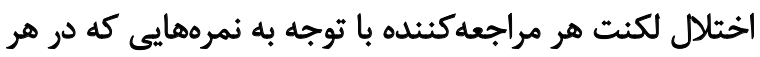

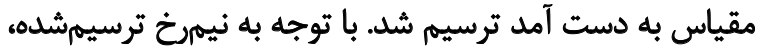

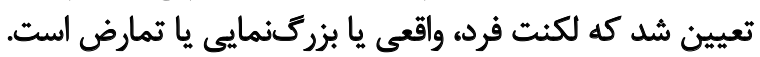

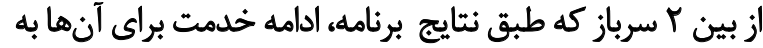

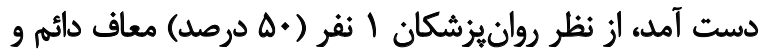

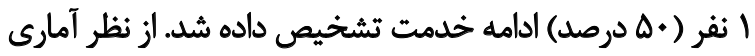

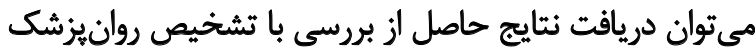

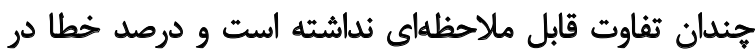

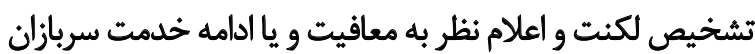

جدول ץ. نتايج حاصل از برنامه در برابر نظر روانيزشكان

\begin{tabular}{|c|c|c|c|c|}
\hline توضيحات & نظل روانيزشيك & تتيجها برنامه & شدت ككثت براساس SSI & شماره مراجعه كنيده \\
\hline & معاف ازز رزم & لكنت واقعى اما بزرىنمايع دارد. & 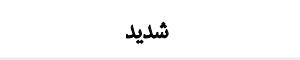 & 1 \\
\hline & معاف از هزوم & الكنت واقعىى & خفيف تا متوسط & r \\
\hline \multirow{5}{*}{ هُراجع شماره ب مشمول بود. } & تأييد ييمارى & الكنت وإقعى & مخفيف تا متوسط & $r$ \\
\hline & معاف از مرنم & لكنت واقعى اما بزرى نمايي دارد. & 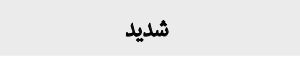 & f \\
\hline & معاف از مرنم & لكنت واقعى اما بزرى نمايع دارد. & 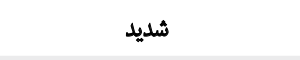 & $\Delta$ \\
\hline & معاقف از مرنم & لكثت واقعى اما بزركنمايع دارد. & 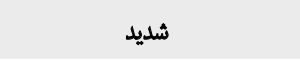 & 8 \\
\hline & نتيجيه يافت نشل. & لكنت واقعى اما بزركنمايع دارد. & مُفيفي تا متوسط & $\gamma$ \\
\hline \multirow[t]{13}{*}{ * } & معاف دائم & بزركنماييى دارد. & شيد & $\wedge$ \\
\hline & معاف از لززم & لكنت واقعى اما بزرك ئمايى دارد. & 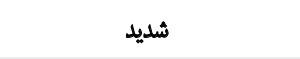 & 9 \\
\hline & معاف الز رزم & لكتث واقعى اما بزرك ثمايى دارد. & 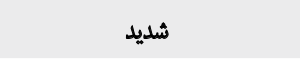 & 1. \\
\hline & 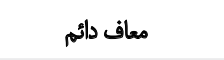 & لكنت وإقعى & 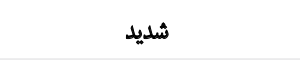 & 11 \\
\hline & معاف أز رزم & لكنت واقعى اما بزركثمايع دارد. & 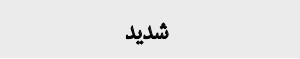 & ir \\
\hline & معاف دائم & لكنت واقعى اما بزركنمايع دارد. & 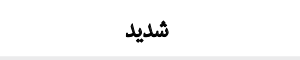 & ir \\
\hline & تمارض دارد. & تمارض دارد. & 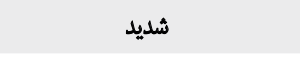 & if \\
\hline & تنيجه يافت تشل. & لكتث واقعى اما بزركنمايع دارد. & 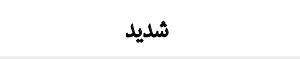 & 10 \\
\hline & 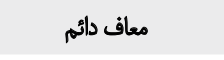 & لكنت واقعى همراه با تمارض كم & 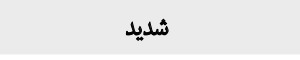 & 18 \\
\hline & معاف از رزم & لكنت واقعى اما بزركنمايع دارد. & 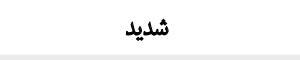 & iv \\
\hline & الدامه خدمت+مارودرمانى & لكنت واققعى & بسيارخفيف & iA \\
\hline & معاف از رزم & لكنت واقعى اما بزركنمايي دارد. & 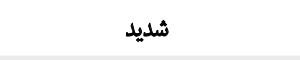 & 19 \\
\hline & معاف الز رزم & الكنت واقعىى & خفيف تامتوسط & r. \\
\hline
\end{tabular}

توانبخننى

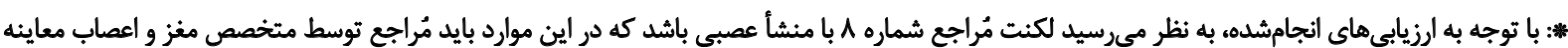


جدول F. بررسى توزيع فراوانى نظر روانيزشك در مقابل نتيجه برنامه در خصوص تمارض لكنت

\begin{tabular}{|c|c|c|c|c|}
\hline سطح معنادارى & ادامه خُدمثت & معاف رزمج & هعاف دائمي & ثظر روانيزشكى \\
\hline \multirow{3}{*}{$+11+\Delta$} & (2) & $(2, د f) r$ & 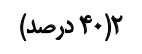 & معاف داثم, (n=ه) \\
\hline & (teg (.). & $(2,2 A N / A) R$ & (N) & معافي \\
\hline & $(\Delta ص, \Delta \cdot)$ & (* مرصد) & $(\Delta \sigma, \Delta \Delta+))$ & ادامه خلدث (n=Y) \\
\hline
\end{tabular}

توانبخننى

با توجه به بررسىهاي انجامشده، بيشتر آزمودنىها در

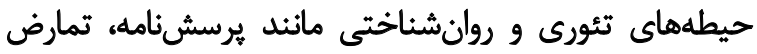

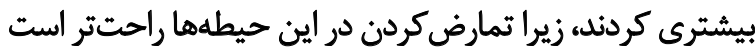

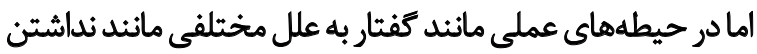

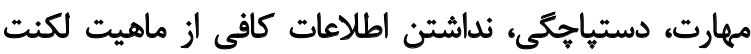

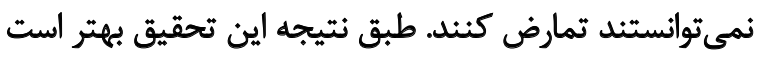

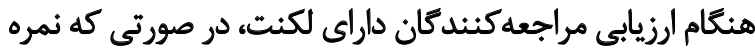

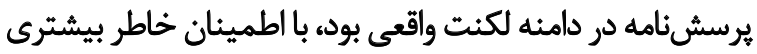

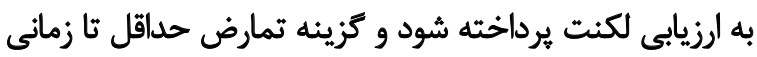

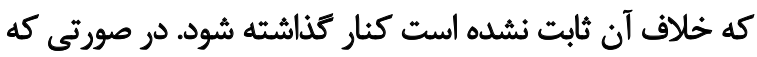

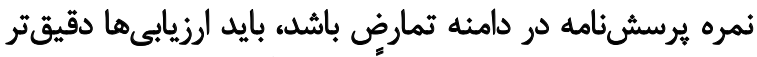

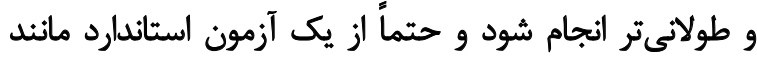

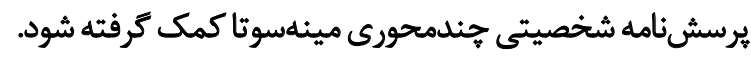

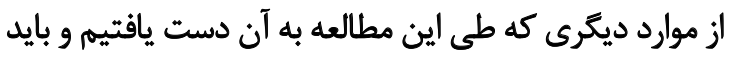

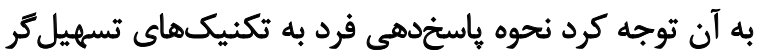

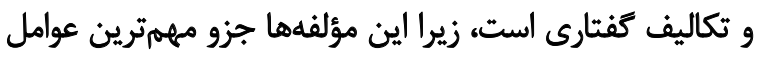

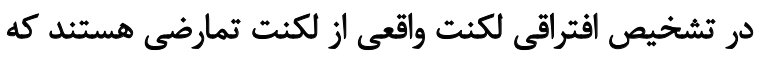

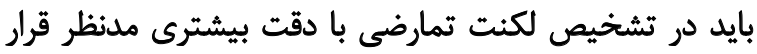

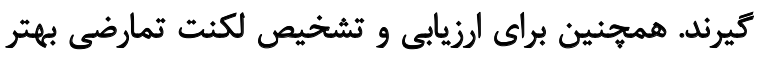

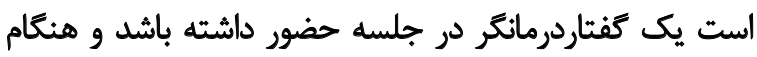
نتيجه

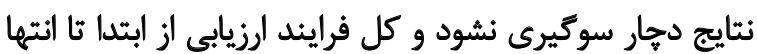

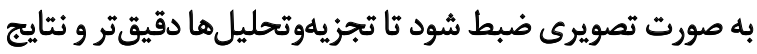
بهدستآمده مستند و در صورت لزوم قابل دفاع و ارائه باشد.

بر اساس قانون نظام وظيفه، مشمولان و سربازانى كه شدت

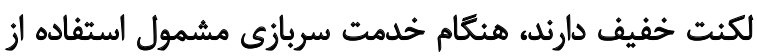

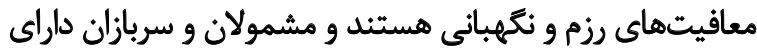

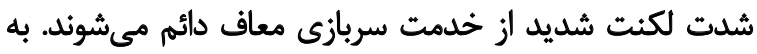

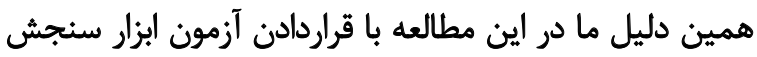

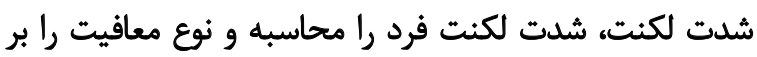

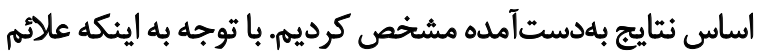

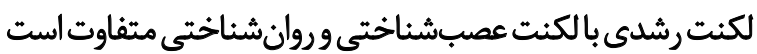

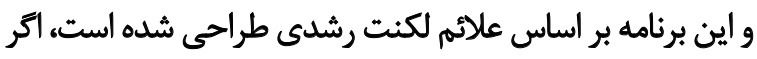

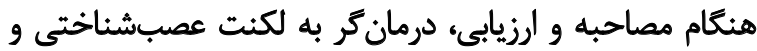

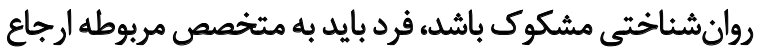

هميجنين براساس نتايج آزمون ابزار سنجش شدت لكنته، شدت

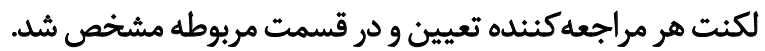

\section{بِ}

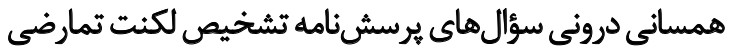

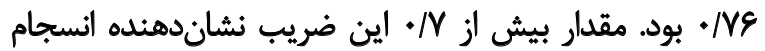

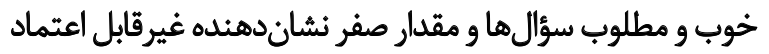

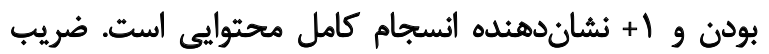

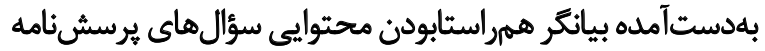

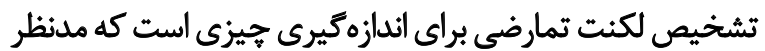
محققان بوده است.

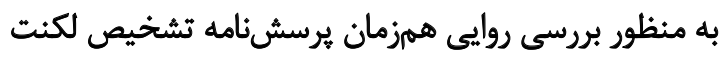

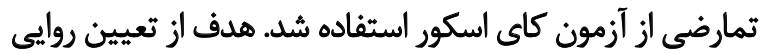

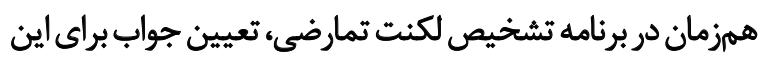

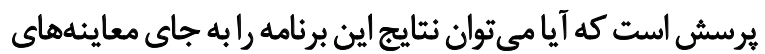

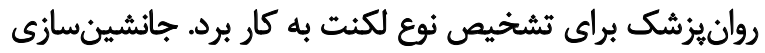

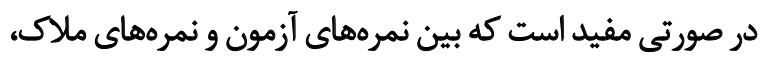

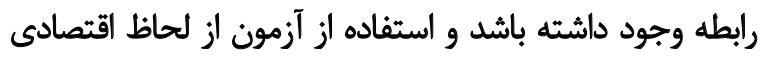

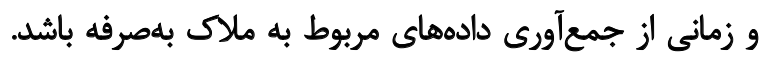

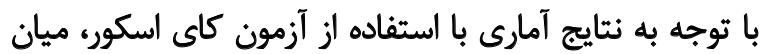

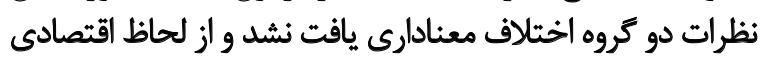

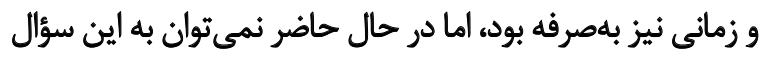

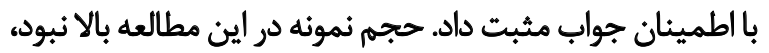

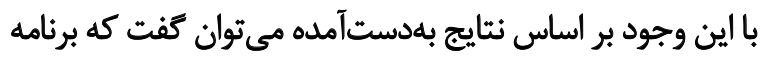
تشخيص لكنت تمارضى روايى همزمان قابل قبولى بلى دارد. به منظور تحليل آمارىهمبستخى يك آزمون، بايد عملكرد

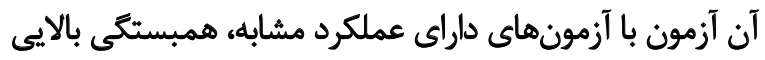

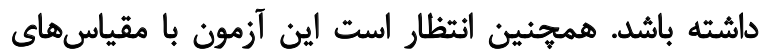

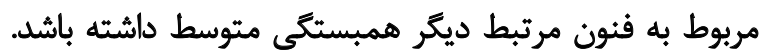

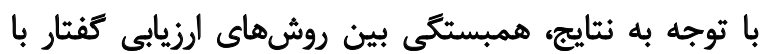

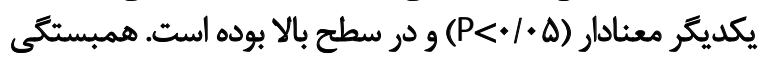

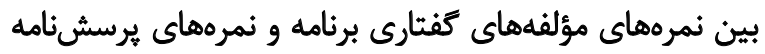

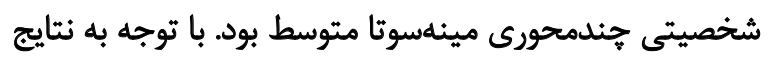

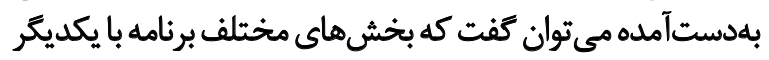
همبستكى مطلوبى دارند. 


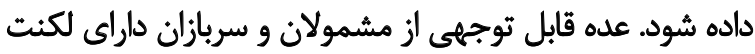

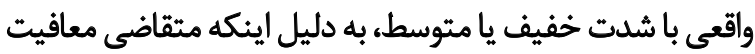

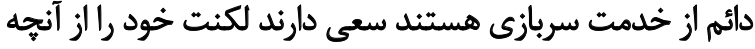

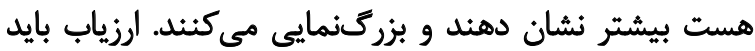

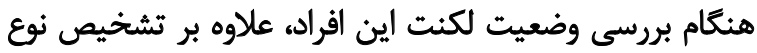

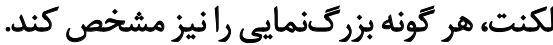

\section{نتيجلمكيرى}

باتوجه به نتايج بهدست آمده مى توان اظهار كرد برنامه تشخيص مناسي

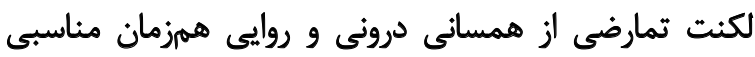

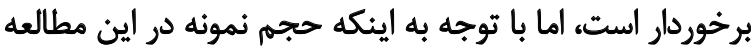

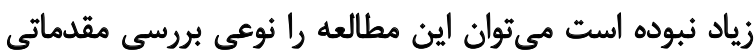

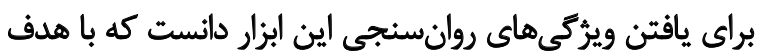

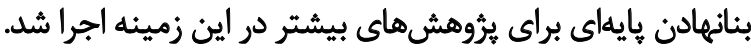

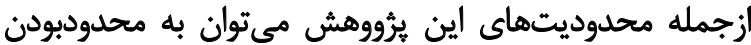

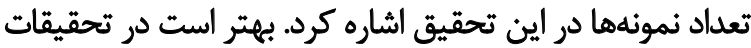

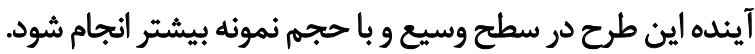

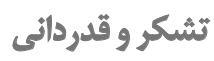

اين يروهش از طرح تحقيقاتى گرفته شده كه با حمايت

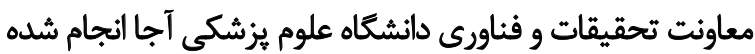

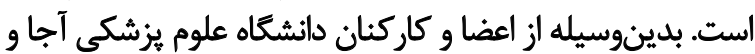

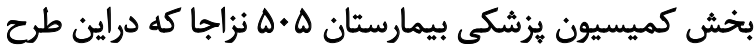

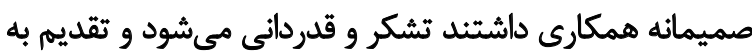

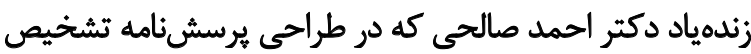
لكنت تمارضى زحمت فراوانى كشيدند. 


\section{References}

[1] Craig A, Blumgart E, Tran Y. The impact of stuttering on the quality of life in adults who stutter. Journal of Fluency Disorders. 2009; 34(2):61-71. doi: 10.1016/j.jfludis.2009.05.002

[2] Guitar B. Stuttering: An integrated approach to its nature and treatment. Philadelphia: Lippincott Williams \& Wilkins; 2013.

[3] Ahangar AA, Bakhtiar M, Mohammadi M, Shakeri-Kavaki M. [The study of the effect of syntactic complexity of noun and verb phrase structure on the occurrence of stuttering in 4-6 year pre-school stuttering persian children (Persian)]. Archives of Rehabilitation. 2013; 14(1):81-90.

[4] Heydari-Nasrabadi M, Kamali M, Arrani-Kashani Z. [Others' presence on the life experiences of people stuttering (Persian)]. Archives of Rehabilitation. 2015; 15(4):78-88.

[5] Nouri N, Nouri N, Abdali H, Shafie M, Karimi H. Stuttering: genetic updates and a case report. Advanced Biomedical Research. 2012; 1:14. doi: 10.4103/2277-9175.96070

[6] Yairi E, Ambrose N. Epidemiology of stuttering: 21 st century advances. Journal of Fluency Disorders. 2013; 38(2):66-87. doi: 10.1016/j.jfludis.2012.11.002

[7] Pourmohammad A, Shafiei M, Kashani M, Salehi A, Shafiei B. [Devising of introductory malingered stuttering-evaluation questionnaire (Persian)]. Journal of Fundamentals of Mental Health. 2014; 16(2): 162-71. doi: 10.13140/RG.2.1.2041.9920

[8] Brocklehurst PH. Stuttering prevalence, incidence and recovery rates depend on how we define it: Comment on Yairi \& Ambrose' article epidemiology of stuttering: $21^{\text {st }}$ century advances. Journal of Fluency Disorders. 2013; 38(3):290-3. doi: 10.1016/j. jfludis.2013.01.002

[9] Azimi T, Pooladi SH, Mahmoodi Bakhtiari B, Haghani H. [Effects of the utterance length on fluency of conversational speech in stuttering persian-speaker children and adults (Persian)]. Archives of Rehabilitation. 2013; 14(3):41-6.

[10] Seery CH. Differential diagnosis of stuttering for forensic purposes. American Journal of Speech-Language Pathology. 2005; 14(4):284-97. doi: 10.1044/1058-0360(2005/028)

[11] Hirkey EA. Forensic verification of stuttering. Journal of Fluency Disorders. 1987; 12(3):197-203. doi: 10.1016/0094-730x(87)90026-x

[12] Bloodstein O. Verification of stuttering in a suspected malingerer. Journal of Fluency Disorders. 1988; 13(2):83-8. doi: $10.1016 / 0094-730 x(88) 90029-0$

[13] Waltz CF, Strickland OL, Lenz ER. Measurement in nursing and health research. 3rd ed. NewYork: Springer; 2005.

[14] Hyrkäs K, Appelqvist-Schmidlechner K, Oksa L. Validating an instrument for clinical supervision using an expert panel. International Journal of Nursing Studies. 2003; 40(6):619-25. doi: 10.1016/s0020-7489(03)00036-1

[15] Polit DF, Beck CT. The content validity index: Are you sure you know what's being reported? Critique and recommendations. Research in Nursing \& Health. 2006; 29(5):489-97. doi: 10.1002/ nur.20147
[16] DeVon HA, Block ME, Moyle-Wright P, Ernst DM, Hayden SJ, Lazzara DJ, et al. A psychometric toolbox for testing validity and reliability. Journal of Nursing Scholarship. 2007; 39(2):155-64. doi: 10.1111/j.1547-5069.2007.00161.x

[17] Roth CR, Aronson AE, Davis LJ. Clinical studies in psychogenic stuttering of adult onset. Journal of Speech and Hearing Disorders. 1989; 54(4):634-46. doi: 10.1044/jshd.5404.634

[18] Stager SV, Jeffries KJ, Braun AR. Common features of fluencyevoking conditions studied in stuttering subjects and controls: An PET study. Journal of Fluency Disorders. 2003; 28(4):319-36. doi: 10.1016/j.jfludis.2003.08.004

[19] Tahmasebi Garmatani N, Shafie B, Feizi A, Salehi A, Howell P. [Determination of the reliability of the stuttering severity instrument-specific adults who stutter (Persian)]. Journal of Research in Rehabilitation Sciences. 2012; 8(4):605-11 